\title{
A Survey of Cannabis Acute Effects and Withdrawal Symptoms: Differential Responses Across User Types and Age
}

\author{
Michelle Sexton, ND, Carrie Cuttler, $\mathrm{PhD}^{2}$ and Laurie K. Mischley, ND, MPH, $\mathrm{PhD}^{3}$
}

\begin{abstract}
Objectives: There is a rapidly evolving legal and medical culture around cannabis, with corresponding changes in the demographics of users. For instance, the percentage of the aging population accessing cannabis is growing substantially, outpacing other age groups. The goals of this study were to describe the acute effects of cannabis, subjective experiences of withdrawal, and beliefs around the addictiveness of cannabis, as well as to determine whether these effects differ as a function of age or reason for use (medical vs. recreational use). It was hypothesized that medical users and younger users would report fewer adverse effects.

Subjects: Survey responses from 2905 cannabis users were analyzed.

Results: Hierarchical logistic regression analyses were used to compare group percentages after statistically controlling for confounding differences in their demographic and cannabis use characteristics. The most commonly endorsed acute effects were improved sleep, more calm/peaceful, desire to eat, more creative, and dry mouth; while the most commonly endorsed withdrawal symptoms were irritability, insomnia, and anxiety. Relative to recreational users, medical users were less likely to report undesirable acute effects but were more likely to report undesirable withdrawal symptoms. Older (50+) individuals reported fewer undesirable acute effects and withdrawal symptoms compared with younger users (18-29). Only 17\% of the total sample reported believing that cannabis is addictive, and this did not vary as a function of reason for use.

Conclusions: Older people and medical users appear to experience acute and withdrawal effects of cannabis differently than recreational and younger users, perhaps because these groups benefit more from the medicinal properties of cannabis. These data can provide descriptive information to help inform health care providers and potential consumers about effects of cannabis use.
\end{abstract}

Keywords: neuropsychological effects, phytocannabinoids, cognitive impairment, medical cannabis

\section{Introduction}

$\mathbf{I}$ NDIVIDUALS PREVIOUSLY NAÏVE to Cannabis sp. may explore its medical application for a variety of symptoms, diagnoses or for weaning from prescription drugs such as opioids. ${ }^{1-5}$ Further, trends toward the legalization of adult use of cannabis are sparking renewed interest in the acute psychotropic effects of cannabis. Prevalence of cannabis use among the 50+ age group, from an ongoing cross-sectional cohort in the United States $(n=47,140)$, increased from $2.8 \%$ to $4.8 \%$ between 2006 and $2013 .^{6}$ The changing demographic of cannabis users calls for the need to further evaluate benefits and risks in different user types and age groups. For instance, the potential for cannabis to impair cognition, memory, and balance may cause concern about potential health harms in older individuals and/or medically compromised individuals

\footnotetext{
${ }^{1}$ Department of Anesthesiology, University of California San Diego, San Diego, CA.

${ }^{2}$ Department of Psychology, Washington State University, Pullman, WA.

${ }^{3}$ Research Institute, Bastyr University, Kenmore, WA.
}

(C) Michelle Sexton et al. 2018; Published by Mary Ann Liebert, Inc. This Open Access article is distributed under the terms of the Creative Commons License (http://creativecommons.org/licenses/by/4.0), which permits unrestricted use, distribution, and reproduction in any medium, provided the original work is properly cited. 
who may already be experiencing some of these symptoms. This leads to a nondirectional hypothesis that older and medical users would report different effects from younger and recreational users. The psychotropic effects profile may be the primary limiting factor in employing cannabis as a medicine. 7

Some cannabis drug effects may be experienced acutely, others continue with ongoing use or emerge over time, and tolerance may develop to certain effects. ${ }^{8-12}$ Heterogeneity across studies impacts the interpretation of findings; however, there is a strong level of evidence for acute and chronic effects of cannabis on cognition, with mixed evidence of recovery of function upon abstinence. ${ }^{13-15}$ In addition, there are gender differences in the experience of both acute effects and withdrawal symptoms. ${ }^{16}$ Anxiety and paranoia are other potential side effects of cannabis; yet a survey reported that $51.8 \%$ of medical users used cannabis to treat anxiety, and another recent report suggests that acute cannabis intoxication decreases anxiety symptoms by $58 \% .^{17-19}$ This incongruence of reported effects may be confusing to new users.

Delta-9 tetrahydrocannabinol (THC) is a partial agonist (low intrinsic efficacy) at cannabinoid $1\left(\mathrm{CB}_{1}\right)$ receptor, responsible for the psychoactive effects of cannabis. ${ }^{20} \mathrm{CB}_{1}$ receptor is found at high levels in the following areas of the brain: cerebellum, hippocampus, basal ganglia, hypothalamus, and basolateral amygdala. ${ }^{21}$ These brain regions regulate motor function, posture, memory, appetite, and fear extinction. The effects of THC are mediated by release or reuptake inhibition of a variety of neurotransmitters. ${ }^{22-25}$ Cannabidiol (CBD) is a low-affinity antagonist of $\mathrm{CB}_{1}$ agonists (such as THC), thus lacking, or modulating, psychoactivity. ${ }^{22,26} \mathrm{CBD}$ therapeutic properties include antipsychotic, anticonvulsant, and anxiolytic, while preclinical studies report antidepressant, anti-inflammatory, antineoplastic, and "alerting" effects. ${ }^{27-40}$ These actions are attributed primarily to binding at noncannabinoid receptors. ${ }^{41,42}$

Potential medical cannabis users and new adult users, previously naïve to the effects, are looking for information related to cost, administration forms, social stigma, and the experience of being "high.", 43 An increasing number of individuals are turning to their doctors who may not be confident in providing information or guidance. ${ }^{44-46}$ Therefore, data from a large-scale cross-sectional survey of regular cannabis users were analyzed to document their subjective acute and withdrawal effects. The authors further aimed to examine differences in these effects as a function of age and type of use, hypothesizing that there may be differential effects. Finally, they report users' beliefs about the addictiveness of cannabis.

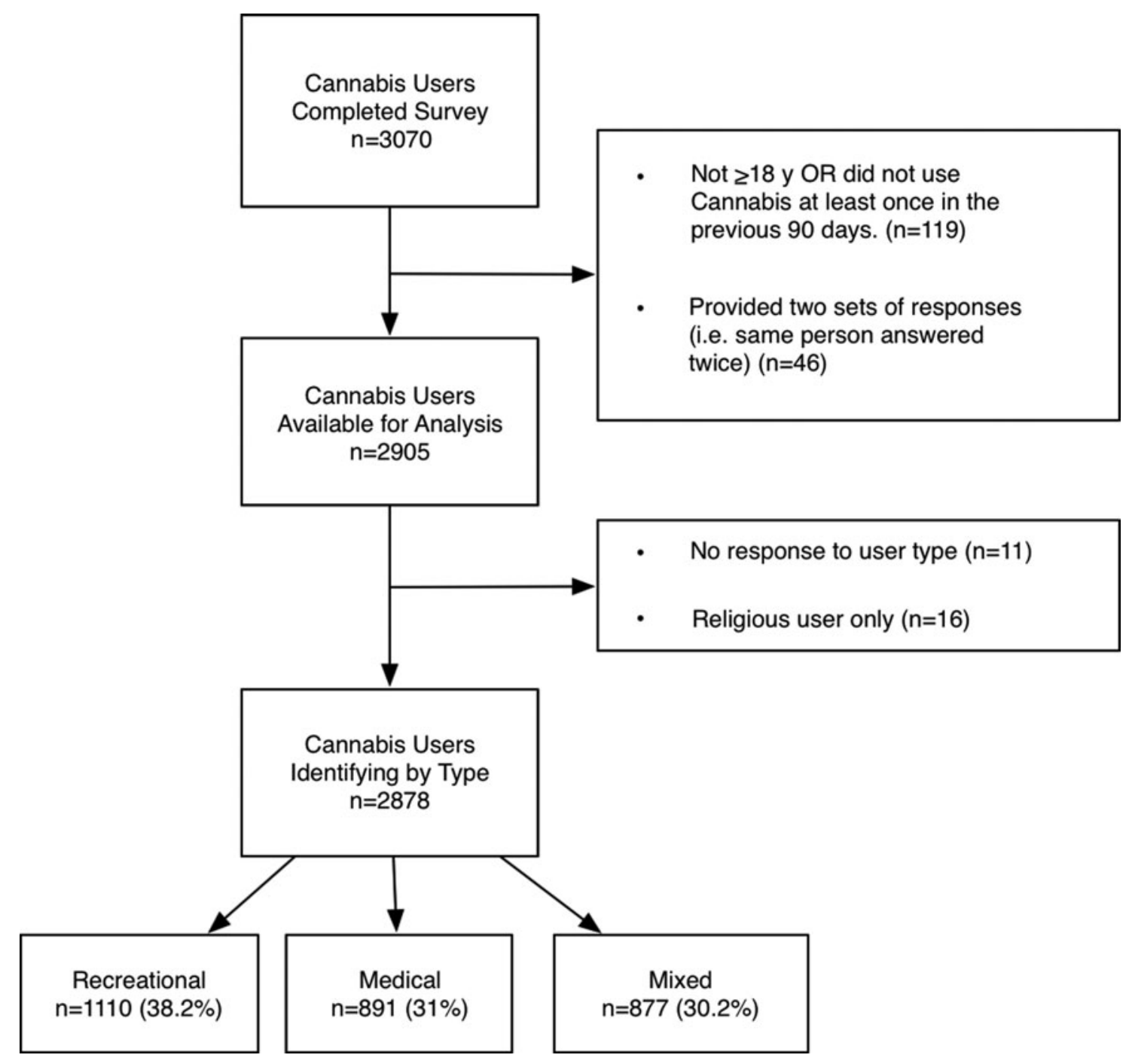

FIG. 1. Flow diagram of participants. 


\section{Materials and Methods}

\section{Participants}

A sample of 3070 participants was recruited through word of mouth, links on a variety of cannabis-related websites, and in Washington State cannabis retail outlets between December 2013 and January 2018. The only inclusion criteria were age $\geq 18$ years and use of cannabis in the past 90 days. One hundred and nineteen respondents did not meet these criteria and were excluded. Forty-six respondents were identified as providing more than one set of responses, so data from their second set of responses were excluded. Therefore, the final sample comprised 2905 adult cannabis users. (Fig 1).

\section{Procedure and materials}

Study data were collected and managed using Research Electronic Data Capture (REDcap), a secure tool allowing participants to directly enter responses. Bastyr University's
Internal Review Board approved the protocol. Participants answered an anonymous online survey containing the items designed to assess cannabis use patterns and effects. No compensation was provided.

Survey questions. The potential acute effects (descriptors) were derived from the existing literature, and cannabis withdrawal symptoms were derived from the Diagnostic and Statistical Manual of Mental Disorders 5 (DSM-5). ${ }^{47}$ This list was circulated to medical professionals utilizing cannabis clinically in an iterative process. The researchers attempted to balance the number of positive and negative descriptors.

Demographic questions. Participants were asked to provide information about their age, gender, ethnicity, employment status, relationship status, highest level of education, and total family income. Response options for each are shown in Table 1.

Table 1. Sample Demographic Characteristics and Cannabis Use PATterns $(N=2905)$

\begin{tabular}{|c|c|c|c|}
\hline \multicolumn{2}{|l|}{ Gender, \% } & \multicolumn{2}{|l|}{ Ethnicity, \% } \\
\hline Male & 53.4 & Caucasian/White & 84.3 \\
\hline Female & 45.5 & Black & 1.8 \\
\hline Missing & 1.1 & Hispanic & 3.8 \\
\hline Age & & Native American & 1.2 \\
\hline Range & $18-80$ & Asian/Pacific Islander & 1.6 \\
\hline Mean & 34.96 & Other & 5.9 \\
\hline Standard deviation & 13.67 & Missing & 1.5 \\
\hline Education, \% & & Income, $\%$ & \\
\hline Less than high school & 2.3 & $<\$ 20,000$ & 19.6 \\
\hline High school/GED & 26.9 & $\$ 20-40,000$ & 23.4 \\
\hline Technical school & 11.1 & $\$ 40-60,000$ & 15.9 \\
\hline Associate & 14.9 & $\$ 60-80,000$ & 11.1 \\
\hline Bachelor's & 29.6 & $\$ 80-100,000$ & 9.3 \\
\hline Master's & 9.1 & $\$ 100-150,000$ & 9.9 \\
\hline Doctorate & 5.1 & $>\$ 150,000$ & 7.7 \\
\hline Missing & 1.1 & Missing & 3.1 \\
\hline Current employment, \% & & Relationship status, \% & \\
\hline Full-time & 52.6 & Single & 40.1 \\
\hline Part-time & 19.8 & Married & 32.6 \\
\hline Unemployed & 12.6 & Domestic & 14.4 \\
\hline Retired & 4.9 & Divorced & 5.5 \\
\hline Disabled & 9.0 & Other & 6.4 \\
\hline Missing & 1.2 & Missing & 0.9 \\
\hline Frequency of use, $\%$ & & Method of use, \% & \\
\hline All day, everyday & 9.2 & Inhalation & 91.3 \\
\hline 5-10 times per day & 12.1 & Oral & 7.4 \\
\hline 1-4 times per day & 42.2 & Other (e.g., topical) & 1.3 \\
\hline 3-6 times per week & 15.4 & Method of selection, $\%$ & \\
\hline 1-3 times per week & 10.3 & High THC & 41.4 \\
\hline 2-3 times per month & 5.2 & High CBD & 32.0 \\
\hline Once a month & 2.0 & Terpenoids & 9.3 \\
\hline Less than once a month & 3.6 & Smell & 43.9 \\
\hline Quantity (per week), \% & & Age of first use, $\%$ & \\
\hline$>1$ oz $(28 \mathrm{~g})$ & 1.8 & $<14$ & 14.4 \\
\hline $1 \mathrm{oz}(28 \mathrm{~g})$ & 4.4 & $14-16$ & 37.1 \\
\hline $1 / 4 \mathrm{oz}(7 \mathrm{~g})$ & 20.9 & $17-18$ & 23.2 \\
\hline $3-5 \mathrm{~g}$ & 30.2 & $19-20$ & 10.0 \\
\hline $1-2 \mathrm{~g}$ & 21.9 & $21-25$ & 8.6 \\
\hline$<1 \mathrm{~g}$ & 20.9 & $>25$ & 3.1 \\
\hline
\end{tabular}

CBD, cannabidiol; THC, delta-9 tetrahydrocannabinol. 
Cannabis use patterns. Participants indicated whether (yes/no) they use cannabis for recreational (adult use) purposes and/or medicinal purposes. They were asked to indicate the method of administration they most commonly use, their frequency of use, quantity of cannabis used per week, and the age they first used cannabis. They were also asked to indicate which of the following they consider important factors when selecting cannabis: high THC content, high CBD content, terpenoid content, and smell.

Acute effects. Participants were provided a list of 45 possible acute effects of cannabis (Table 2) and were asked to use a yes/no scale to indicate which immediate effects they experience (selecting as many as applied).

Withdrawal. Participants were asked to use a yes/no scale to report 13 withdrawal symptoms they have experienced with discontinuation of cannabis for $\geq 72 \mathrm{~h}$. A not applicable (n/a) response option was included for those who had never discontinued cannabis for $\geq 72 \mathrm{~h}$ or who had not experienced any withdrawal symptoms.

Addiction. Participants used a yes/no scale to indicate whether they had ever had trouble reducing or stopping their use of cannabis, and they used a yes/no/I don't know scale to indicate whether they believe cannabis is addictive.

\section{Data analysis}

The data were analyzed using IBM SPSS 23. Percentages were computed, and hierarchical logistic regression analyses were used to compare group percentages after statistically controlling for confounding differences in their demographic and cannabis use characteristics. Due to the large number of comparisons and the large sample size, only results with a $p$ value $\leq 0.001$ were considered statistically significant.

\section{Results}

\section{Characteristics of the cohort}

The sample of 2878 cannabis users was classified as "medical" ( $n=891 ; 31.0 \%)$, "recreational" $(n=1110 ; 38.2 \%)$, or "mixed" (selected both medical/recreational; $n=877 ; 30.2 \%$ ) (Fig. 1). The sample of 2855 individuals who provided their age were further classified by age as young: 18-29 $(n=1300$; $44.8 \%)$; middle: $30-49(n=1048 ; 36.1 \%)$; or older: $50+$ $(n=507 ; 17.5 \%)$. Table 1 displays the demographic characteristics and cannabis use patterns of the complete sample. Supplementary Tables S1 and S2 (with consolidated response options) provide this information as a function of user type and age grouping, respectively.

Acute effects. Table 2 shows the overall percentage of respondents endorsing each of the acute effects. As shown in the table, the most commonly reported effects $(>50 \%$ of total) were improved sleep $(82.1 \%)$, more calm/peaceful $(79.7 \%)$, desire to eat $(72.7 \%)$, more creative $(72.4 \%)$, dry mouth (63\%), less anxious/fearful $(56.7 \%)$, and more "inward" focus $(50.1 \%)$.

Supplementary Table S3 shows the percentages of medical, recreational, and "mixed" (medical/recreational) cannabis users who endorsed each of the acute effects. Statistical comparisons of these groups (with the confounding group differences highlighted in Supplementary Table S1 controlled) indicated that medical users were significantly less likely than recreational users to endorse some "undesirable" effects, such as being more forgetful, increased anxiety, and

Table 2. Percentage of Total Respondents Endorsing Various Acute Effects of Cannabis

\begin{tabular}{|c|c|c|c|}
\hline \multicolumn{2}{|l|}{ Cognitive, $\%$} & \multicolumn{2}{|l|}{ Psychological, \% } \\
\hline Sense of clarity/perspective & 44.5 & More calm/peaceful & 79.7 \\
\hline Short-term memory problems & 42.2 & Less anxious or fearful & 56.7 \\
\hline More articulate/communicative & 41.3 & Increased motivation & 47.2 \\
\hline Improved concentration & 40.1 & Altered sense of time & 37.6 \\
\hline More forgetful & 36.5 & Enthusiastic & 37.3 \\
\hline Difficulty finding words & 18.1 & Less motivation & 23.5 \\
\hline Difficulty concentrating & 16.4 & Paranoia & 14.5 \\
\hline Memory improvement & 13.6 & Apathetic & 8.7 \\
\hline Difficulty making decisions & 10.2 & Increased anxiety & 8.6 \\
\hline Confusion & 4.9 & Hallucinations & 3.8 \\
\hline Long-term memory problems & 4.2 & & \\
\hline \multicolumn{2}{|l|}{ Physiological, \% } & \multicolumn{2}{|l|}{ Movement, \% } \\
\hline Improved sleep & 82.1 & Desire to clean & 40.3 \\
\hline Desire to eat (munchies) & 72.7 & Desire to stretch/exercise & 37.2 \\
\hline Dry mouth & 63.0 & Desire to be still/couch-lock & 31.1 \\
\hline Increased sex drive & 48.7 & Poor balance/feel unsteady & 5.8 \\
\hline Tired/sleepy & 45.9 & Lack of coordination & 5.4 \\
\hline Stimulated/energized & 44.4 & \multicolumn{2}{|l|}{ Artistic/social, \% } \\
\hline Affects dreams & 33.9 & More creative & 72.4 \\
\hline Loss of appetite & 9.6 & More "inward" focus & 50.1 \\
\hline Hurts lungs & 7.6 & Better social interactions & 46.9 \\
\hline Diminished sex drive & 6.5 & Musical & 41.9 \\
\hline Disrupted sleep & 5.2 & More extraverted, "outward" focus & 24.8 \\
\hline \multirow[t]{2}{*}{ Dizziness } & 5.0 & Worse social interactions & 12.2 \\
\hline & & Less creative & 3.4 \\
\hline
\end{tabular}


"couch-lock." Figure 2a shows that medical users were significantly more likely than recreational users to endorse some "desirable" effects: memory improvement, more articulate, less anxious/fearful, increased motivation, improved sleep, and better social interactions.

Further, responders were segregated by age, and it was found that older and middle-age individuals reported fewer undesirable cognitive, psychological, and physiological effects (Supplementary Table S4 and Fig. 2b).

Withdrawal symptoms. Overall, $35.2 \%$ of responders indicated that withdrawal symptoms were not applicable to them. The most commonly reported withdrawal symptoms were irritability $(33.7 \%)$, insomnia $(30.3 \%)$, and anxiety
$(22.7 \%)$. Fewer than $20 \%$ of respondents endorsed the remaining withdrawal symptoms (Table 3 ).

Comparisons of user types indicated that medical and mixed-type cannabis users reported more undesirable withdrawal symptoms than recreational users. Specifically, as shown in Figure 3, medical and mixed users differed significantly from recreational users with respect to reporting anxiety, loss of productivity, and loss of appetite as symptoms of withdrawal (Supplementary Table S5). Mixed users also reported insomnia more than recreational users. Finally, medical users were significantly more likely to report nausea than recreational users.

Older individuals were significantly less likely than middle-age and younger individuals to endorse several of
FIG. 2. Significant differences in desirable or undesirable acute effects. Bar plots show the raw percentages of each age group selecting acute effects, with significant differences between groups using chi square analyses in reported acute effects. (a) Differences in "desirable" acute effects by user type: ${ }^{*} p<0.001$ from recreational users; $* * p<0.001$ from recreational and mixed users; $\# p<0.001$ from medical users. (b) Significant differences in "undesirable" acute effects by age grouping. ${ }^{*} p<0.001$ from both young and middle age groups; $* * p<0.001$ from the young and older age groups; $* * * p<0.001$ from the young age group. Color images are available online.

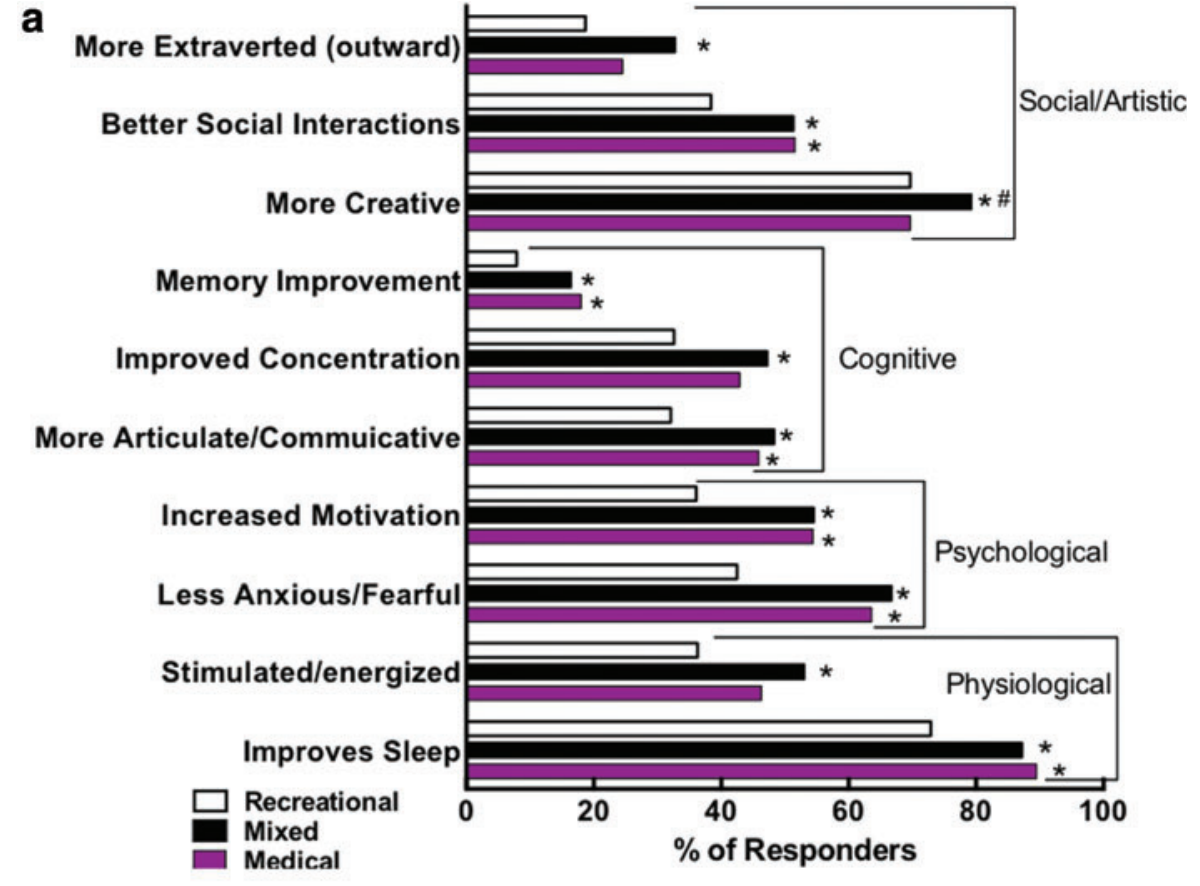

b

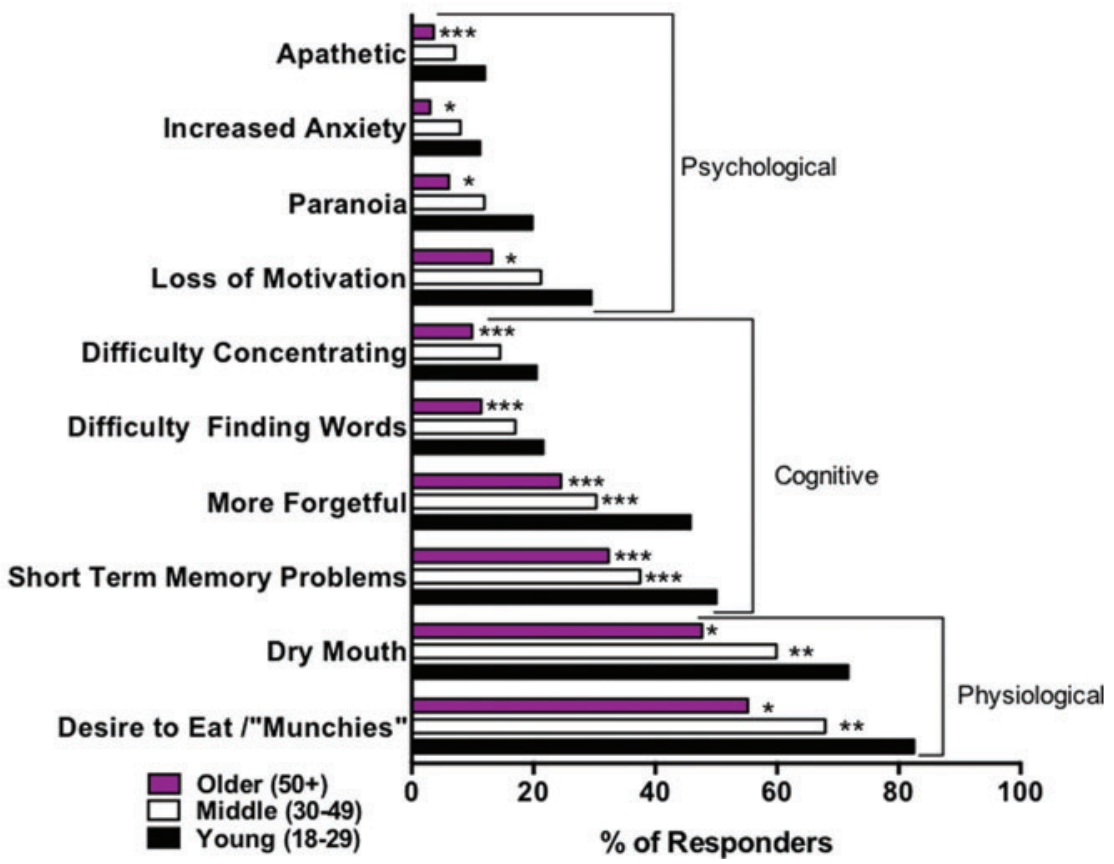


Table 3. Percentage of Total Respondents Who Reported Various WithdraWal Symptoms

\begin{tabular}{llll}
\hline Withdrawal symptoms, \% & & & \\
Not applicable & 35.2 & Tiredness & 8.2 \\
Irritability & 33.7 & Nausea & 7.0 \\
Insomnia/interrupted sleep & 30.3 & Improved productivity & 4.8 \\
Anxiety & 22.7 & Weight loss & 3.9 \\
Loss of appetite & 18.8 & Sweating & 3.9 \\
Vivid dreams & 17.3 & Tremor & 1.4 \\
Loss of productivity & 12.4 & Salivation & 0.6 \\
Addictiveness, \% & & & \\
Is not addictive & 68.1 & Don't know if addictive & 14.8 \\
Is addictive & 17.0 & Have had trouble & 16.7 \\
& & stopping & \\
& & &
\end{tabular}

Survey responders were asked to report yes/no to indicate whether they experience each symptom when removing cannabis for $72 \mathrm{~h}$, or not applicable if they never experience any symptoms or have never removed cannabis for $\geq 72 \mathrm{~h}$. They could respond yes/no to trouble stopping cannabis and yes/no/don't know to the question about addictiveness.

the withdrawal symptoms, including irritability, insomnia, and loss of appetite (Supplementary Table S6).

Addiction. As shown in Table 3, the majority of respondents reported believing that cannabis is not addictive, with only $17 \%$ reported believing it is addictive and a similar percentage (16.7\%) reporting trouble stopping cannabis. The results of group comparisons revealed that, after controlling for the confounding differences between user types and age groups, a lower percentage of the older cannabis users reported believing that cannabis is addictive than younger and middle-age users (Fig. 4 and Supplementary Tables S5 and S6).

\section{Discussion}

The purpose of this study was to document acute cannabis effects and withdrawal effects as functions of user types and age grouping. Because $91 \%$ of this cohort report using inhalation as their primary method of administration, the rapid kinetic and high bioavailability of cannabinoids through this route would predict acute effects to be widely experienced. ${ }^{48}$ In general, the results here mirror acute effects reported in the literature such as desire to eat, dry mouth, and cognitive effects. However, these results expand upon previous research by demonstrating differential effects based on the type of user and age, with medical users and older users reporting fewer undesirable acute effects and recreational users and older users reporting fewer withdrawal symptoms.

Consistent with previous research, the present findings indicate that acute cannabis effects include a degree of cognitive impairment. However, subjective perception of improved cognitive function (including improved concentration [40.1\%]; having a sense of clarity/perspective [44.5\%]; more articulate/communicative [41.3\%]) was high for this entire cohort. Moreover, differential cognitive effects were observed as the older cohort was significantly less likely than the younger individuals to report being forgetful, difficulty concentrating, making decisions, and finding words.

Memory is known to start declining after age 50, and difficulty finding words (a symptom of mild cognitive impairment) is estimated to affect $10 \%-20 \%$ of individuals aging $65+{ }^{49}$ Therefore, age differences in reports of undesirable cognitive effects may reflect the fact that older individuals are already experiencing cognitive decline, and thus may be more likely to attribute these symptoms to aging rather than cannabis. Alternatively, changes in the endocannabinoid system across the life span may reflect differential effects of cannabis

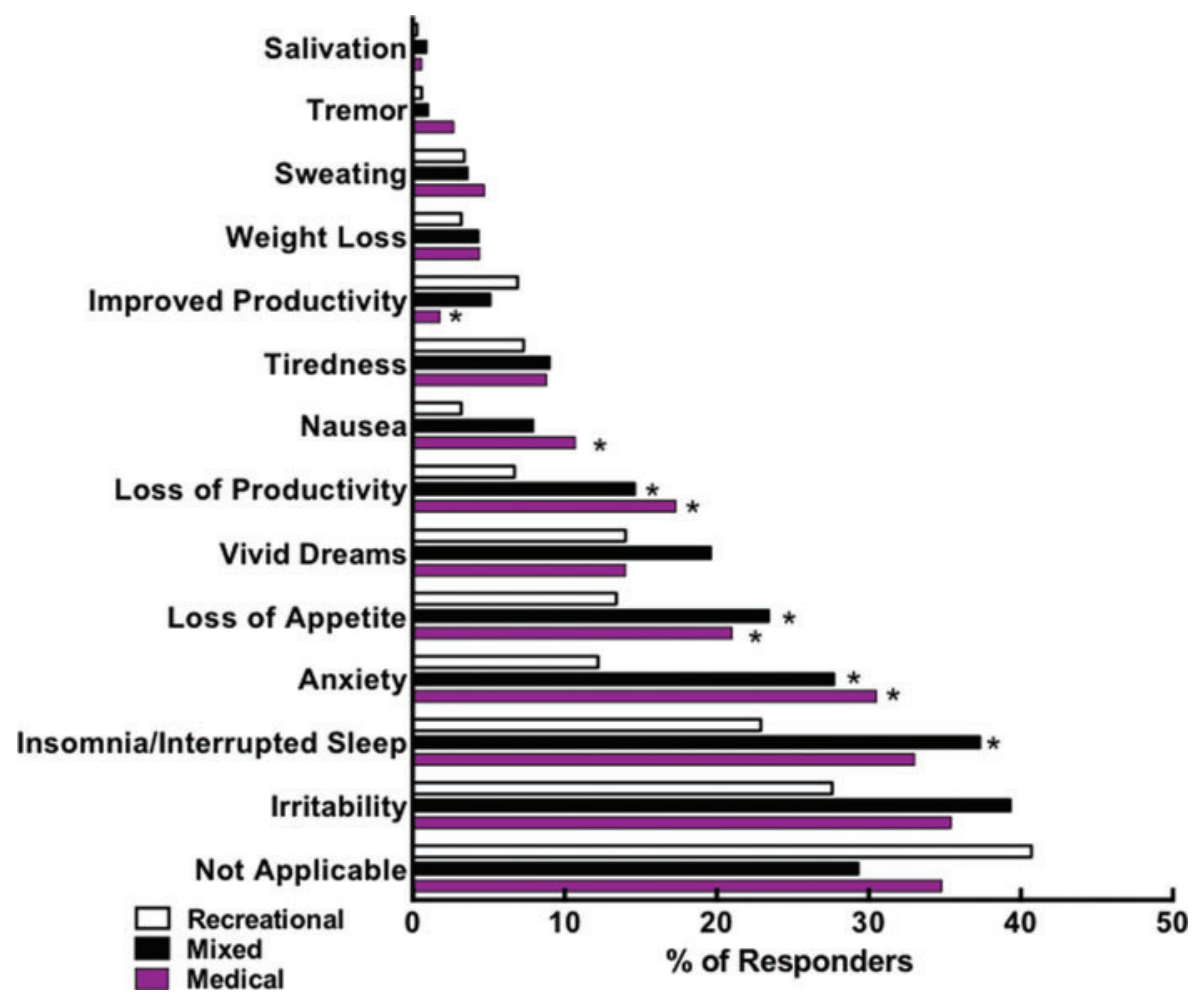

FIG. 3. Differential withdrawal effects based on user type: bar graph shows the raw percentages of each user type selecting each effect. Significant differences across groups were determined using $p \leq 0.001$, after statistically controlling for potentially cofounding group differences: $*$ indicates significant difference from recreational users. Color images are available online. 
FIG. 4. Beliefs about addictiveness among young, middle, and older age groups: bar graph shows the raw percentage of each age group endorsing trouble stopping using cannabis and selecting yes/ no/don't know responses to the question "Do you believe that cannabis is addictive?" **Indicates significant difference from both younger and middle-age groups with $p \leq 0.001$ after statistically controlling for potentially confounding group differences. Color images are available online.

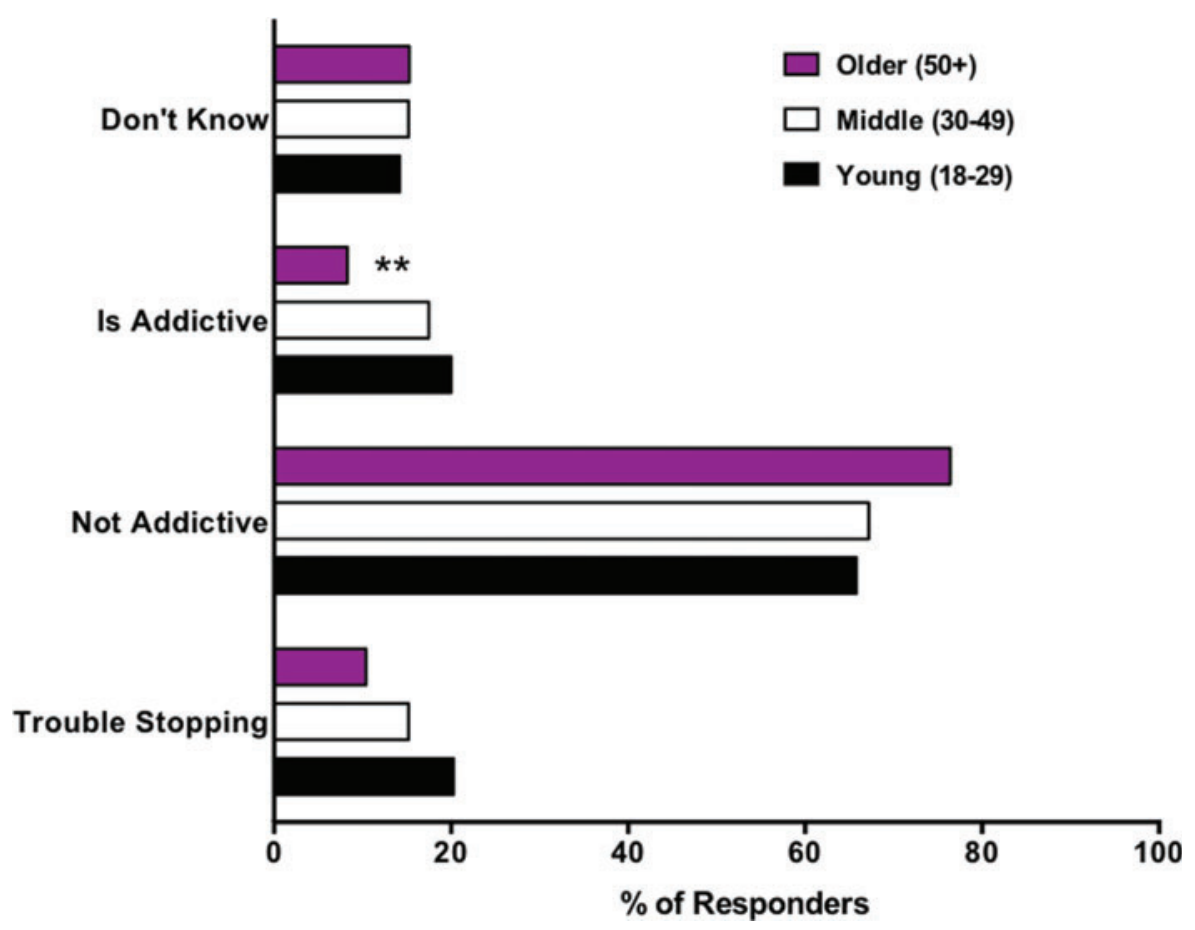

on the "mature" brain. ${ }^{50,51}$ Specifically, endocannabinoid system activity declines with age. ${ }^{52}$

An alternative interpretation challenges the existing paradigm of negative neurocognitive effects. A chronic low dose of THC showed differential effects in mice, boosting performance in older animals while dropping performance in younger mice. ${ }^{51}$ This low dose regulated $\mathrm{CB}_{1}$ gene transcription in a protective and cognitive performanceenhancing manner, and this effect was absent in $\mathrm{CB}_{1}$ knockout animals. In addition, THC may have a biphasic effect on cognition, or even procognitive effects associated with acetylcholinesterase inhibition. ${ }^{53,54}$ The older cohort and medical users were significantly more likely to be using $\mathrm{CBD}$, which could indicate that they may have been receiving lower doses of THC compared with other age groups (not a confounder in this analysis).

In addition to reporting fewer undesirable cognitive effects, older individuals were significantly less likely to report increased anxiety, paranoia, apathy, and decreased motivation. Similarly, medical users were more likely than recreational users to endorse feeling less anxious or fearful and increased motivation. The overall high rates of endorsement of "increased motivation" were somewhat surprising. Since amotivational syndrome was first described in 1972, a fear has been perpetuated that cannabis will sap users of their capacity to function normally in society. ${ }^{55}$ Despite ongoing research on this topic, there is still controversy with some reports finding no differences in global motivation, while other data still support the concept. ${ }^{56-58}$ Nevertheless, the differential effect found between medical/mixed use and recreational use may reflect intention. Medical users are typically seeking improvement in quality of life and increased function, while research suggests that recreational use may be more related to leisure time and relaxation. ${ }^{17,59}$

Overall, the results were equivocal with regard to whether acute cannabis intoxication was associated with feeling tired/ sleepy $(45.9 \%)$ or stimulated/energized $(44.4 \%)$, with significantly more mixed users than recreational users reporting stimulation and reports of feeling tired/sleepy decreasing as a function of age. While the mechanisms driving these results are currently unclear, they may be attributed to timing of use, type of cannabis used (such as the THC or CBD potency), intent behind use, and/or relief from medical symptoms. ${ }^{17}$ Reports of feeling a lack of coordination or unsteadiness were low, with only $5.8 \%$ of responders endorsing this acute effect. Given that poor balance/feeling unsteady can be a symptom of some disease processes or a natural consequence of aging, fall risk is an important consideration. However, note that the older cohort and medical users did not report this symptom with higher frequency.

Collectively, the results reported here indicate that medically compromised and older individuals (who may have more health concerns) may not experience the same neurocognitive consequences of cannabis as recreational users, consistent with another preliminary prospective report. ${ }^{60}$ This may reflect a sense of improved wellness associated with medical cannabis use and/or loss of neurodevelopmental vulnerability associated with some medical conditions and the drugs used to treat them. ${ }^{61}$ The same may hold true for older users who are more likely to have symptoms of aging such as arthralgia, lower back pain, arthritis, dementia, or neurodegeneration. Indeed, an observational retrospective study of cannabis use in patients with Parkinson's disease concluded that overall symptom improvement $(82 \%)$ was not accompanied by major adverse effects. ${ }^{62}$ Finally, results from this study echo other recent research reporting that medical cannabis use may be associated with improved executive functioning, potentially as a result of reduced symptom burden and improved well-being. ${ }^{51}$ This calls into question whether "impairment" or "intoxication" associated with recreational use is a valid descriptor for medical use. Prospective studies using standardized 
preparations will need to confirm whether any potential risk of cognitive deficit or other adverse effects outweigh the overall benefits for chronically ill or aging people.

Overall, $35.2 \%$ of the total sample reported that withdrawal symptoms were not applicable to them (either because they have never discontinued cannabis use for $\geq 72 \mathrm{~h}$ or because they simply have not experienced any withdrawal effects). For those acknowledging withdrawal effects, older users were less likely to report irritability, insomnia/interrupted sleep, anxiety, and loss of appetite. In contrast, medical/mixed users were significantly more likely to report anxiety, loss of productivity, and loss of appetite than recreational users. The latter symptoms may reflect true withdrawal or could be confounded by a rebound effect (return of medical symptoms treated by cannabis).

The majority of respondents $(68.1 \%)$ believe that cannabis is not addictive, with older individuals being significantly more likely to report that cannabis is not addictive than younger or middle-age adults. Correspondingly, the percentage of responders reporting trouble stopping cannabis was $16.7 \%$, and did not vary as a function of user type or age. These results are somewhat consistent with previously reported rates of cannabis use disorder (30\%) and addiction to cannabis (9\%), and suggest that a minority of people do become addicted to cannabis. ${ }^{63,64}$ However, the present finding that $68.1 \%$ of respondents indicated believing that cannabis is not addictive is much higher than recent findings that $22.4 \%$ of adults in the United States believe that marijuana is not addictive. This discrepancy is likely a function of the different samples surveyed in these two studies (regular cannabis users vs. the general population). ${ }^{65}$

The strengths of this study include the large sample size, which allows for comparison of different types of cannabis users and age cohorts, the assessment of a large number of acute and withdrawal effects, and the anonymous nature of the survey, which reduces socially desirable response. Nevertheless, the study has several limitations due to its observational nature. Since cannabis user type and age were not manipulated, the results only imply associations. The data are self-reported retrospective data, which are subject to recall biases. These data also do not allow for investigation into the effects of different cannabis chemotypes or potencies, and therefore it is unclear whether differences in relative CBD or THC content are driving some of the effects. ${ }^{66}$ They also did not permit for investigation into effects of duration or timing of use. Further, there is likely a self-selection bias: this sample would not reflect effects of individuals who tried cannabis and found the effects intolerable, and thus discontinued use. Similarly, $90 \%$ of this cohort were using cannabis on a regular basis (daily or weekly use), and previous research indicates that naïve and regular users may experience different acute effects potentially due to the development of tolerance to some side effects. ${ }^{12,52-57}$ For instance, tolerance to the acute cognitive effects occurs with regular use, and these effects become less prominent when consistent THC dosing is maintained. ${ }^{67}$

\section{Conclusion}

As with most drugs, the acute and withdrawal effects of cannabis are likely time- and dose sensitive, subject to individual variability and environmental effects. As such, it is difficult to draw definitive conclusions about universal effects from these data. Nevertheless, with the rapid expansion of recreational cannabis legalization and an increasing prevalence of use by older individuals, information on the acute and withdrawal effects of cannabis is needed to assist in individual decision making around cannabis use. In addition to providing this information, these data indicate that medical users and older individuals $(>50)$ may experience a more favorable side effect profile than recreational and younger adult users, and that recreational and older users may experience fewer withdrawal symptoms. Future studies need to address potential cognitive benefits of low-dose THC in older adults.

\section{Author Disclosure Statement}

L.K.M. is a member of the Scientific Advisory Board of Next Frontier Pharmaceuticals. L.K.M. and M.S. are authors of "Cannabis Use Survey: Insights, Confessions, and Opinions." All other authors have no competing financial interests.

\section{References}

1. Fairman BJ. Trends in registered medical marijuana participation across 13 US states and District of Columbia. Drug Alcohol Depend 2016;159:72-79.

2. Park JY, Wu LT. Prevalence, reasons, perceived effects, and correlates of medical marijuana use: A review. Drug Alcohol Depend 2017;177:1-13.

3. Hamilton HA, Brands B, Ialomiteanu AR, et al. Therapeutic use of cannabis: Prevalence and characteristics among adults in Ontario, Canada. Can J Public Health 2017;108:e282-e287.

4. Abuhasira R, Schleider LB, Mechoulam R, et al. Epidemiological characteristics, safety and efficacy of medical cannabis in the elderly. Eur J Intern Med 2018;49:44-50.

5. Corroon JM, Jr., Mischley LK, Sexton M. Cannabis as a substitute for prescription drugs - A cross-sectional study. J Pain Res 2017;10:989-998.

6. Han BH, Sherman S, Mauro PM, et al. Demographic trends among older cannabis users in the United States, 2006-13. Addiction 2017;112:516-525.

7. Dạbrowski G, Skrajda M. Cannabinoids from Cannabis sp.: Mechanism of their activity and potential health benefits in human body. J Educ Health Sport 2017;7:936-945.

8. Newmeyer MN, Swortwood MJ, Abulseoud OA, et al. Subjective and physiological effects, and expired carbon monoxide concentrations in frequent and occasional cannabis smokers following smoked, vaporized, and oral cannabis administration. Drug Alcohol Depend 2017;175: 67-76.

9. Desrosiers NA, Ramaekers JG, Chauchard E, et al. Smoked cannabis' psychomotor and neurocognitive effects in occasional and frequent smokers. J Anal Toxicol 2015;39: 251-261.

10. Theunissen EL, Kauert GF, Toennes SW, et al. Neurophysiological functioning of occasional and heavy cannabis users during THC intoxication. Psychopharmacology (Berl) 2012;220:341-350.

11. D'Souza DC, Ranganathan M, Braley G, et al. Blunted psychotomimetic and amnestic effects of delta-9tetrahydrocannabinol in frequent users of cannabis. Neuropsychopharmacology 2008;33:2505-2516. 
12. Auer R, Vittinghoff E, Yaffe K, et al. Association between lifetime marijuana use and cognitive function in middle age: The Coronary Artery Risk Development in Young Adults (CARDIA) study. JAMA Intern Med 2016;176:352361.

13. Broyd SJ, van Hell HH, Beale C, et al. Acute and chronic effects of cannabinoids on human cognition-A systematic review. Biol Psychiatry 2016;79:557-567.

14. Schreiner AM, Dunn ME. Residual effects of cannabis use on neurocognitive performance after prolonged abstinence: A meta-analysis. Exp Clin Psychopharmacol 2012;20:420429.

15. D'Souza DC, Cortes-Briones JA, Ranganathan M, et al. Rapid changes in $\mathrm{CB}_{1}$ receptor availability in cannabis dependent males after abstinence from cannabis. Biol Psychiatry Cogn Neurosci Neuroimaging 2016;1:60-67.

16. Cuttler C, Mischley LK, Sexton M. Sex differences in cannabis use and effects: A cross-sectional survey of cannabis users. Cannabis Cannabinoid Res 2016;1:166-175.

17. Sexton M, Cuttler C, Finnell JS, et al. A cross-sectional survey of medical cannabis users: Patterns of use and perceived efficacy. Cannabis Cannabinoid Res 2016;1:131138.

18. Freeman D, Dunn G, Murray RM, et al. How cannabis causes paranoia: Using the intravenous administration of 9tetrahydrocannabinol (THC) to identify key cognitive mechanisms leading to paranoia. Schizophr Bull 2015;41: 391-399.

19. Cuttler C, Spradlin A, McLaughlin RJ. A naturalistic examination of the perceived effects of cannabis on negative affect. J Affect Disord 2018;235:198-205.

20. Huestis MA, Gorelick DA, Heishman SJ, et al. Blockade of effects of smoked marijuana by the $\mathrm{CB}_{1}$-selective cannabinoid receptor antagonist SR141716. Arch Gen Psychiatry 2001;58:322-328.

21. Mackie K. Cannabinoid receptors: Where they are and what they do. J Neuroendocrinol 2008;20(Suppl 1):10-14.

22. Pertwee RG. The diverse $\mathrm{CB}_{1}$ and $\mathrm{CB}_{2}$ receptor pharmacology of three plant cannabinoids: Delta9-tetrahydrocannabinol, cannabidiol and delta9-tetrahydrocannabivarin. Br J Pharmacol 2008;153:199-215.

23. Velenovska M, Fisar Z. Effect of cannabinoids on platelet serotonin uptake. Addict Biol 2007;12:158-166.

24. Mendiguren A, Aostri E, Pineda J. Regulation of noradrenergic and serotonergic systems by cannabinoids: Relevance to cannabinoid-induced effects. Life Sci 2018;192: $115-127$.

25. Maldonado R, Berrendero F, Ozaita A, et al. Neurochemical basis of cannabis addiction. Neuroscience 2011;181:117.

26. Laprairie RB, Bagher AM, Kelly ME, et al. Cannabidiol is a negative allosteric modulator of the cannabinoid $\mathrm{CB}_{1}$ receptor. Br J Pharmacol 2015;172:4790-4805.

27. McPartland JM, Duncan M, Di Marzo V, et al. Are cannabidiol and delta(9)-tetrahydrocannabivarin negative modulators of the endocannabinoid system? A systematic review. Br J Pharmacol 2015;172:737-753.

28. Russo EB, Guy GW, Robson PJ. Cannabis, pain, and sleep: Lessons from therapeutic clinical trials of Sativex, a cannabisbased medicine. Chem Biodivers 2007;4:1729-1743.

29. Leweke FM, Piomelli D, Pahlisch F, et al. Cannabidiol enhances anandamide signaling and alleviates psychotic symptoms of schizophrenia. Transl Psychiatry 2012;2: e94.
30. Rohleder C, Muller JK, Lange B, et al. Cannabidiol as a potential new type of an antipsychotic. A critical review of the evidence. Front Pharmacol 2016;7:422.

31. Devinsky O, Cross JH, Wright S. Trial of cannabidiol for drug-resistant seizures in the Dravet syndrome. N Engl J Med 2017;377:699-700.

32. Bergamaschi MM, Queiroz RH, Chagas MH, et al. Cannabidiol reduces the anxiety induced by simulated public speaking in treatment-naive social phobia patients. Neuropsychopharmacology 2011;36:1219-1226.

33. Zuardi AW, Rodrigues NP, Silva AL, et al. Inverted Ushaped dose-response curve of the anxiolytic effect of cannabidiol during public speaking in real life. Front Pharmacol 2017;8:259.

34. de Mello Schier AR, de Oliveira Ribeiro NP, Coutinho DS, et al. Antidepressant-like and anxiolytic-like effects of cannabidiol: A chemical compound of Cannabis sativa. CNS Neurol Disord Drug Targets 2014;13:953-960.

35. Cuba LF, Salum FG, Cherubini K, et al. Cannabidiol: An alternative therapeutic agent for oral mucositis? J Clin Pharm Ther 2017;42:245-250.

36. McAllister SD, Soroceanu L, Desprez PY. The antitumor activity of plant-derived non-psychoactive cannabinoids. J Neuroimmune Pharmacol 2015;10:255-267.

37. Devinsky O, Cilio MR, Cross H, et al. Cannabidiol: Pharmacology and potential therapeutic role in epilepsy and other neuropsychiatric disorders. Epilepsia 2014;55:791-802.

38. Crippa JA, Derenusson GN, Ferrari TB, et al. Neural basis of anxiolytic effects of cannabidiol (CBD) in generalized social anxiety disorder: A preliminary report. J Psychopharmacol 2011;25:121-130.

39. Stockings E, Zagic D, Campbell G, et al. Evidence for cannabis and cannabinoids for epilepsy: A systematic review of controlled and observational evidence. J Neurol Neurosurg Psychiatry 2018;89:741-753.

40. Szaflarski JP, Bebin EM, Cutter G, et al. Cannabidiol improves frequency and severity of seizures and reduces adverse events in an open-label add-on prospective study. Epilepsy Behav 2018. [Epub ahead of print]; DOI: 10.10.16/j.yebeh.2018.07.020.

41. Morales P, Hurst DP, Reggio PH. Molecular targets of the phytocannabinoids: A complex picture. Prog Chem Org Nat Prod 2017;103:103-131.

42. Kaplan JS, Stella N, Catterall WA, et al. Cannabidiol attenuates seizures and social deficits in a mouse model of Dravet syndrome. Proc Natl Acad Sci U S A 2017;114: 11229-11234.

43. Ko G, Hendin B, Mindra M, Jung S. 6 Common concerns regarding medical marijuana. Pract Pain Manag. 2016; 16, https://www.practicalpainmanagement.com/treatments/ pharmacological/non-opioids/6-common-concerns-regardingmedical-marijuana, accessed October 24, 2018.

44. Barker J. Clinical challenges in the growing medical marijuana field. R I Med J (2013) 2018;101:13-14.

45. Brooks E, Gundersen DC, Flynn E, et al. The clinical implications of legalizing marijuana: Are physician and nonphysician providers prepared? Addict Behav 2017;72:1-7.

46. Braun IM, Wright A, Peteet J, et al. Medical oncologists' beliefs, practices, and knowledge regarding marijuana used therapeutically: A nationally representative survey study. J Clin Oncol 2018;36:1957-1962.

47. Katz G, Lobel T, Tetelbaum A, et al. Cannabis withdrawal-A new diagnostic category in DSM-5. Isr J Psychiatry Relat Sci 2014;51:270-275. 
48. Huestis MA. Human cannabinoid pharmacokinetics. Chem Biodivers 2007;4:1770-1804.

49. Petersen RC. Clinical practice. Mild cognitive impairment. N Engl J Med 2011;364:2227-2234.

50. Marco EM, Laviola G. The endocannabinoid system in the regulation of emotions throughout lifespan: A discussion on therapeutic perspectives. J Psychopharmacol 2012;26:150 163.

51. Bilkei-Gorzo A, Albayram O, Draffehn A, et al. A chronic low dose of delta(9)-tetrahydrocannabinol (THC) restores cognitive function in old mice. Nat Med 2017;23:782-787.

52. Di Marzo V, Stella N, Zimmer A. Endocannabinoid signalling and the deteriorating brain. Nat Rev Neurosci 2015; 16:30-42.

53. Calabrese EJ, Rubio-Casillas A. Biphasic effects of THC in memory and cognition. Eur J Clin Invest 2018;48:e12920.

54. Eubanks LM, Rogers CJ, Beuscher AE 4th, et al. A molecular link between the active component of marijuana and Alzheimer's disease pathology. Mol Pharm 2006;3:773777.

55. Le Dain Commission CG. Cannabis: A Report of the Commission of Inquiry into the Non-Medical Use of Drugs. Ottawa: Information Canada, 1972.

56. Duncan DF. Lifetime prevalence of "amotivational syndrome" among users and non-users of hashish. Psychol Addict Behav 1987;1:114-119.

57. Barnwell SS, Earleywine M, Wilcox R. Cannabis, motivation, and life satisfaction in an internet sample. Subst Abuse Treat Prev Policy 2006;1:2.

58. Volkow ND, Swanson JM, Evins AE, et al. Effects of cannabis use on human behavior, including cognition, motivation, and psychosis: A review. JAMA Psychiatry 2016;73:292-297.

59. Osborne GB, Fogel C. Understanding the motivations for recreational marijuana use among adult Canadians. Subst Use Misuse 2008;43:539-572; discussion 573-579, 585587.
60. Gruber SA, Sagar KA, Dahlgren MK, et al. Splendor in the grass? A pilot study assessing the impact of medical marijuana on executive function. Front Pharmacol 2016;7:355.

61. Chapkis W, Webb RJ. Cannabis and Consciousness, in Dying to Get High. New York and London: New York University Press, 2008:115-135.

62. Balash Y, Bar-Lev Schleider L, Korczyn AD, et al. Medical cannabis in Parkinson disease: Real-life patients' experience. Clin Neuropharmacol 2017;40:268-272.

63. Hasin DS, Saha TD, Kerridge BT, et al. Prevalence of marijuana use disorders in the United States between 20012002 and 2012-2013. JAMA Psychiatry 2015;72:12351242.

64. Lopez-Quintero C, Perez de los Cobos J, Hasin DS, et al. Probability and predictors of transition from first use to dependence on nicotine, alcohol, cannabis, and cocaine: Results of the National Epidemiologic Survey on Alcohol and Related Conditions (NESARC). Drug Alcohol Depend 2011;115:120-130.

65. Keyhani S, Steigerwald S, Ishida J, et al. Risks and benefits of marijuana use: A national survey of U.S. adults. Ann Intern Med 2018;169:282-290.

66. Russo EB. Taming THC: Potential cannabis synergy and phytocannabinoid-terpenoid entourage effects. Br J Pharmacol 2011;163:1344-1364.

67. Colizzi M, Bhattacharyya S. Cannabis use and the development of tolerance: A systematic review of human evidence. Neurosci Biobehav Rev 2018;93:1-25.

Address correspondence to: Michelle Sexton, $N D$ 9500 Gillman Drive \#0898 La Jolla, CA 92093

E-mail:msexton@ucsd.edu 